\title{
IMPLICIT EFFECTS OF MOTIVATIONAL CUES AND COLOR STIMULI ON CREATIVITY.
}

\author{
Laurens Rook, \\ Delft University of Technology. \\ l.rook@tudelft.nl
}

\begin{abstract}
The present research explored the notion that the meaning of the color red varies depending on regulatory focus, with implicit effects on creative thinking in a Remote Association Test. Specifically, inducing promotion (vs. prevention) enhances creativity, because red (vs. blue or grey) then triggers the meaning of approach and potential success. Two laboratory studies revealed this regulatory focus-color interaction showing that promotion yields more creativity for red, whereas this effect is not observed for prevention. These results show that the effect of red on creativity depends on someone's motivational state, and not only contribute to existing research on the contextdependence of color, but also add to the growing research on creativity and design cognition.
\end{abstract}

Keywords: self-regulation, color, creativity.

\section{INTRODUCTION}

Can exposure to color implicitly steer someone's creative endeavors? The present research suggests that color stimuli - and especially the color red indeed have that hidden potential, but that we are capable of dealing with this influence, once we account for the motivational orientation of the designer during the creative act. To foreshadow the theorizing developed in the present study, it is maintained that a motivational principle called regulatory focus serves to moderate the hidden effects of color stimuli on creative thinking. Once we understand the nature of one's regulatory focus, we therefore are capable of predicting - and ultimately managing - someone's creative performance in the face of color.

\section{REGULATORY FOCUS, COLOR, AND CREATIVE THINKING}

\section{REGULATORY FOCUS THEORY}

Regulatory focus theory (RFT; Higgins, 1997) is one of the most influential motivational theories in social psychology. According to RFT, human functioning can generally be understood as deriving from two distinct motivational systems: the promotion system and the prevention system. The promotion system refers to a strategic inclination toward advancement, growth, and accomplishment; the prevention system, on the other hand, must be perceived as a strategic inclination towards security, safety, and responsibility (Crowe \& Higgins, 1997; Higgins, 1997). RFT recognizes that the promotion and prevention system can depend on individual differences in personality (Lockwood, Jordan \& Kunda, 2002), but also posits that each motivational system can be situationally induced, in which case promotion and prevention respectively function as motivational strategies.

A vast literature exists showing that promotion and prevention cause people to respond differently to information, problems and tasks. For instance, promotion-focused people tend to display risky processing styles in which gains, hits and successes are actively approached, whereas preventionfocused people rather display vigilant processing styles in which losses, errors and failures are actively avoided (Crowe \& Higgins, 1997; Higgins, 1997). In that light, prior studies have found that promotionfocused people often perform faster, better, and more efficient in many performance tasks, essentially because they keep a constant eye on the 
price; prevention-focused people, in contrast, are slower and more conservative in their actions, because they are too obsessed with possible mistakes.

Of particular relevance to the present discussion, studies in which RFT was applied to creativity settings have repeatedly shown that people with promotion focus generally perform better in a creative task than people with prevention focus. In one study, it proved sufficient to provide participants in the promotion condition with a children's cartoon depicting a maze, a mouse, and a piece of cheese located outside of the maze. Asking participants to find a way out of the maze - and on the way out finding the price (i.e., a nice chunk of cheese) - was enough to render salient a promotion focus that caused them to generate more and radically novel alternatives in a subsequent creativity task. In the prevention condition, the cartoon depicted a maze, a mouse, and an owl located outside of the maze. Asking participants to find a way out of the maze - and on the way out finding a danger (i.e., the owl that is mice's natural enemy) - was enough to render salient a prevention focus that caused people to avoid radical alternatives in the following creativity task, thereby blocking creativity (Friedman \& Förster, 2001).

Summarizing, RFT is an influential motivational theory in social psychology that also is successfully applied to creativity. It is widely accepted that people generally perform better in a creative task after being primed with promotion than with prevention.

\section{COLOR PSYCHOLOGY}

In the domain of social psychology, the study of color stimuli is currently gaining momentum after several findings that color may serve as an implicit (read: automatic) factor in performance. Automaticity research has collected cumulative evidence for implicit effects of various stimuli on people's accuracy in judgment, decision making, and behavior (Bargh \& Chartrand, 1999). A central notion of automaticity research is the existence of a perception-behavior link, which causes people to display specific behavior due to mere perception of a specific context (Dijksterhuis \& Bargh, 2001). This perception-behavior link also seems to exist for color stimuli in various performance settings. For instance, professional ice hockey and football teams wearing black apparently display more aggressive behavior (Frank \& Gilovich, 1988). Recent studies have particularly emphasized the impact of the color red on human functioning. One study published in Nature claimed that red increases social dominance and the likelihood of winning: contestants in martial arts combats wearing red during the 2004 Olympic Games won more fights than fighters wearing other colors (Hill \& Barton, 2005).

Importantly, a recent literature on the automaticity of color psychology paints a different picture. Building on the assumption that red can be associated with danger and failure, many studies have now shown that people non-consciously wish to avoid exposure to the color red (Elliot et al., 2007, 2009; Maier et al., 2008; Lichtenfeld et al., 2009). Apparently, the intimidation value of the color red is so deeply rooted in humans that people have a strong implicit tendency to display avoidance behavior when exposed to it. Along such lines, several experiments have found that even the mere perception of mundane red-colored stimuli (such as paper binders, pens, leaflet covers, Lego pieces, and typos) prior to an achievement task can hamper a participant's performance (Elliot et al., 2007).

\section{REGULATORY FOCUS, COLOR, AND CREATIVITY}

Creative thinking is a context-dependent phenomenon, hence by definition sensitive to implicit influences (Zhong, Dijksterhuis \& Galinsky, 2008). Indeed, one study in Science confirmed that perception of the color red negatively influences creative thinking; in contrast, the authors showed that exposure to the color blue had a positive effect on creativity (Mehta \& Zhu, 2009).

The key question that thus arises is: under what circumstances, if any, can the color red have a positive influence on creative thinking? Recent insights in color psychology recognize that color in general, and red in particular, is differentially 
appreciated in different contexts. For instance, where perception of red equals danger in performance settings, it triggers attraction for men when a woman wears a red dress (Elliot \& Niesta, 2008). Also, people seem to prefer red over any other color in a friendly environment, but not in hostile surroundings (Maier, Barchfeld, Elliot \& Pekrun, 2009). Thus, color can carry a particular meaning depending on various contextual characteristics, and - which is of vital importance for the present discussion - motivational processes.

This observation renders the study into the role of color stimuli in creative thinking prone to RFT predictions. The central claim of this paper is that the color red can have a positive effect on creative thinking depending on a person's regulatory focus on promotion or prevention. Because people with promotion focus by inclination are not afraid of a possible danger, they may rather interpret this as a challenge and feel attracted to it. When exposed to the color red, it therefore seems likely that promotion focused-people will equal redness with potential success. In contrast, people with prevention focus by definition interpret information in terms of possible traps, and will indeed interpret red as something dangerous that should be avoided. This different meaning of the color red as a function of one's regulatory focus may lead to differential performance in a creative thinking test.

\section{OVERVIEW OF THE EXPERIMENTS}

This hypothesis was put to the test in two laboratory experiments. In both studies, participants first received the following RFT manipulation: a picture with a cartoon mouse and maze. In the promotion condition, participants had to complete a maze with a piece of cheese located outside. In the prevention condition, to find a way out for the mouse, participants had to finish a maze with an owl flying around (Friedman \& Förster, 2001). Second, participants received a color manipulation, which differed per experiment. Third, in both studies participants took part in a Remote Association Test (RAT; Mednick, 1962). The RAT was specifically developed as a creative thinking test, and is widely used for the study of insight and creative problem- solving. In the RAT, participants are confronted with three test words (e.g., map-book-world) and invited to come up with a fourth target word that can be associated with each of these three words in a way that makes sense in everyday language (atlas). The RAT can be administered using any number of questions. Some triads are more difficult to solve than others (e.g., it is simple to link the words cottage-swiss-cake to target word cheese, moderately difficult to connect the words sandwichhouse-golf to target word club, and very difficult to associate the words way-ground-weather to target word fair; see Bowden \& Beeman, 2003). Success on the RAT correlates with success in classic creativity and insight problems, and is therefore ideal for investigating creative thinking.

\section{METHOD EXPERIMENT 1}

\section{PARTICIPANTS}

Subjects were 75 undergraduates of a university in the Netherlands ( 43 men and 14 women) with an average age of 21.05 years. Participation was limited to people that were not color blind. Participants were randomly assigned to the experimental conditions of a 2 (regulatory focus: promotion, prevention) $\mathrm{X} 2$ (color: red, blue) factorial design on creativity.

\section{MATERIALS AND PROCEDURE}

Upon arrival in the laboratory, participants were invited to take part in a 1 hour session presumably dedicated to diverse psychological studies. They first received the RFT manipulation with the cartoon mouse and maze. This took 1-2 min to finish. Second, participants were provided with an instruction leaflet and a closed box of Lego ${ }^{\mathrm{TM}}$. This box contained 160 differently shaped bricks, and depending on experimental condition, participants either received a box that consisted entirely of red or blue pieces. A Minolta CS-100 spectrophotometer was used to determine the spectral data parameters: red (LCh [52.2; 77.8; 14.0]), and blue (LCh [60.2; $51.0 ; 21.9])$. These values indicated that chroma (C) was different for the two colors, but lightness (L) was similar (Fairchild, 2005). Participants were invited to take 30 min to build a 3D scale model of an art object to be placed on the university campus 
using the Lego ${ }^{T M}$ pieces. Thus, during $30 \mathrm{~min}$ of working on their $3 \mathrm{D}$ art object, participants were exposed to one single color.

Immediately after finishing, participants received three examples of the RAT problem, and were asked to determine for twelve other RAT triads selected from Bowden and Beeman (2003) what the target words were. Of the latter triads, four items were easy to solve, four items were of moderate difficulty, and four were very difficult to solve. The total number of correct solutions served as a measure of creativity. On completion, participants were probed for awareness regarding the purpose of the experiment ("What do you think we were trying to test?"), debriefed, sworn secrecy, thanked and sent away.

\section{RESULTS}

An analysis of variance revealed a significant interaction effect of regulatory focus and color on creativity, $F(1,53)=9.03, p<.01, \eta^{2}=.15$. People with a promotion focus displayed more creativity in the face of red $(M=.62, S D=.13)$ than in the face of blue $(M=.46, S D=.15)$, whereas people with a prevention focus displayed more creativity in the face of blue $(M=.57, S D=.08)$ than in the face of red $(M=.50, S D=.19)$ (see Figure 1$)$. Further analysis indeed showed a significant effect of regulatory focus within the color red, $F(1,55)=$ 4.42, $p<.04, \mathrm{n}^{2}=.07$, and of regulatory focus within the color blue, $F(1,55)=4.15, p<.05, \eta^{2}=.07$, and a significant effect of color within promotion focus, $F(1,55)=8.72, p<.01, \eta^{2}=.14$, but not within prevention focus, $F(1,55)=1.56$, ns.

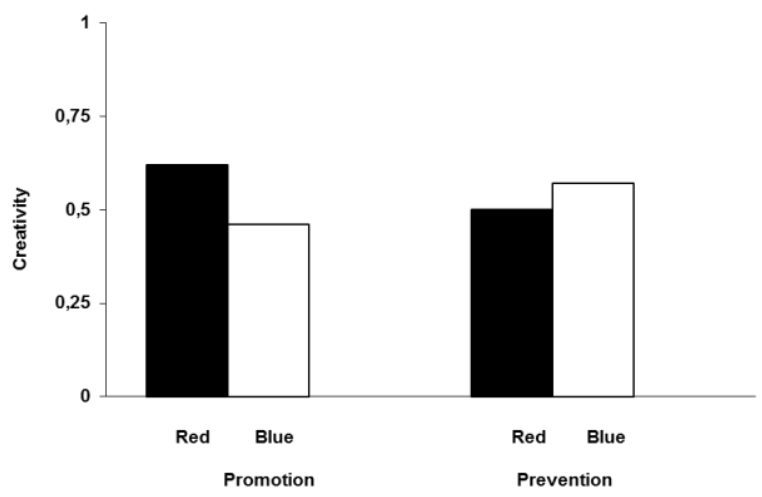

Figure 1. Regulatory focus $X$ color on creativity (Experiment 1).

\section{DISCUSSION EXPERIMENT 1}

Experiment 1 revealed that regulatory focus and color stimuli have implicit effects on people's creative thinking in a RAT task. That is, especially for people with induced promotion focus, creativity is implicitly facilitated in the face of red, whereas this effect was not observed for people induced with prevention focus. This confirmed this paper's prediction. However, even though the hue and lightness scores of the red and blue bricks used in this study were relatively similar, there was a large difference between the two colors with respect to chroma. To rule out the possibility that the observed effect thus was in fact confounded, a second study was conducted using a different control color, in an experimental design in which the parameters that generally define a color space were kept constant (Fairchild, 2005).

\section{METHOD EXPERIMENT 2}

\section{PARTICIPANTS}

Subjects were 63 undergraduates of a university in the Netherlands ( 40 men and 23 women) with an average age of 19.87 years. Participation was limited to people that were not color blind. Participants were randomly assigned to the experimental conditions of a 2 (regulatory focus: promotion, prevention) $\mathrm{X} 2$ (color: red, grey) factorial design on creativity.

\section{MATERIALS AND PROCEDURE}

The procedure of Experiment 2 was largely identical to Experiment 1, but consisted of a different color manipulation, in which grey served as the control color. In color studies, non-colors such as white, black or grey are typically used as the neutral control condition with which experimental chromatic color conditions are compared (Elliot et al., 2007).

Participants first received the RFT manipulation consisting of the maze pictures, followed by the RAT triads - all materials the same as in Experiment 1. This time, though, the RAT was presented on one page A4 that was either completely set in red or grey typo. Those colors were selected using the HSV color model that defines a color space in terms of hue, saturation, and value/brightness (Fairchild, 2005). 
Accordingly, red was equated on saturation and value/brightness (red: hsv[0, 87, 72]) and the achromatic grey, which has no saturation, was equated on value/brightness (grey: hsv[-, 0, 72]). Thus, depending on experimental condition, participants were exposed to one single color during the time they worked on their RAT task. On completion, participants filled out the final questionnaire that was identical to the one administered in Experiment 1.

\section{RESULTS}

An analysis of variance revealed a significant interaction effect of regulatory focus and color on creativity, $F(1,59)=10.09, p<.01, \eta^{2}=.15$. Promotion yielded more creativity for red $(M=.47$, $S D=.14)$ than for grey $(M=.31, S D=.21)$; prevention yielded more creativity for grey $(M=.44$, $S D=.16)$ than for red $(M=.33, S D=.15)$ (see Figure 2). Further analysis indeed showed a significant effect of regulatory focus within the color red, $F(1,59)=5.61, p<.03, \eta^{2}=.08$, and within the achromatic grey, $F(1,59)=4.17, p<.05, \eta^{2}=.06$, and a significant effect of color within promotion focus, $F(1,59)=7.72, p<.01, \eta^{2}=.11$, but not within prevention focus, $F(1,59)=2.68$, ns.

Using a different color model and a different control color, this was a replication of Experiment 1.

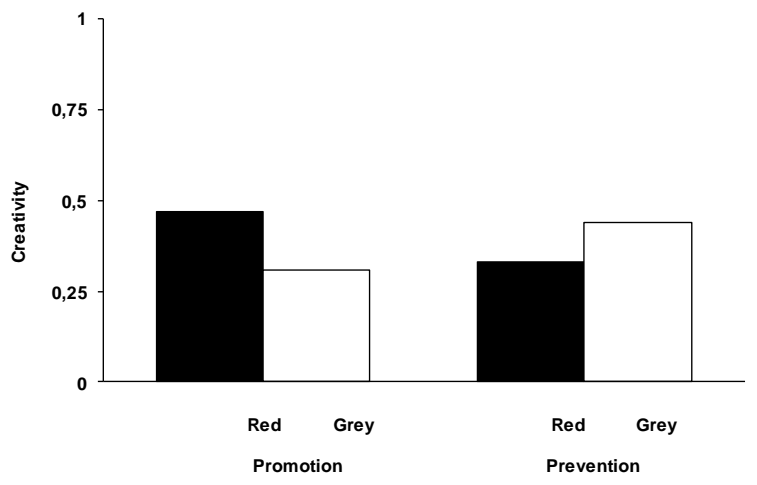

Figure 2. Regulatory focus $X$ color on creativity (Experiment 2).

\section{GENERAL DISCUSSION}

Can exposure to color implicitly steer someone's creative endeavors? The current investigation showed that inducing people with a promotion focus automatically made people perform better in a creative thinking task in the face of red, because the mere presence of red for those people triggered the meaning of approach - in other words, the color red rendered salient feelings associated with challenge, and this indeed yielded success. For people induced with prevention focus, in contrast, performance in a creative thinking task was hampered in the face of red, because red for those people triggered the meaning of danger, which non-consciously blocked subsequent creative thinking. The present research therefore provided evidence that color stimuli - and most notably the color red - indeed have the hidden potential to enhance or constrain creativity, depending on someone's regulatory focus.

This investigation contributes to the cumulating evidence in cognitive psychology for the motivational embeddedness of color; it demonstrates that inducing a promotion rather than a prevention focus can establish implicit red-success linkages in creative performance. Thus far, color psychology maintained that the color red in general tends to negatively influence cognitive task performance (Elliot et al., 2007, 2009; Maier et al., 2008), unless red is presented in romantic or friendly environments (Elliot \& Niesta, 2008; Maier et al., 2009). The present study, however, provided first evidence that red also can have implicit positive effects in the case of creativity. Especially when people are framed in terms of possible gains and successes, the danger of perceiving red can be turned into an opportunity that boosts creative thinking.

Along such lines, this investigation also contributes to the growing literature on creative and design cognition. The present research is in concordance with the growing evidence in the field of creative cognition that insight and creativity can be situationally induced (e.g., Friedman \& Förster, 2002, 2005), and extends this literature by pointing to the role of color stimuli. Moreover, this research adds to the growing literature on design cognition that explores the relationship between cognitive and 
perceptual processes during design tasks. Prior study has for instance found that the color of sketching tools can negatively influence the design process, because the availability of color seemingly causes designers to display suboptimal creative behavior (Damle \& Smith, 2009). The present research seems to suggest that this may not necessarily and always be the case: the effects of color on ideation are more likely subject to the interplay between a designer's regulatory focus and color itself. Admittedly, in the current investigation, the positive influence that the color red exerted on the design process was derived from a creative thinking paradigm that does not entirely capture the nature of idea sketching behavior, but given the key importance of sketching in design tasks (Kavakli, Scrivener, \& Ball, 1998), it is an interesting option for future research to explore if and under what circumstances the color red can positively influence the creative sketching behavior of designers.

In conclusion, color stimuli can have an implicit effect on creativity, but we are capable of predicting - and ultimately managing - someone's creative performance in the face of color once we understand the nature of one's regulatory focus on promotion or prevention.

\section{REFERENCES}

Bargh, J. A., \& Chartrand, T. L. (1999). The unbearable automaticity of being. American Psychologist, 54, 462-476.

Bowden, E. M., \& Beeman, M. J. (2003). Normative data for 144 compound remote associate problems. Behavior Research Methods, Instruments, \& Computers, 35, 634-639.

Crowe, E., \& Higgins, E. T. (1997). Regulatory focus and strategic inclinations: Promotion and prevention in decision-making. Organizational Behavior and Human Decision Processes, 69, 117132.
Damle, A., \& Smith, P. J. (2009). Biasing cognitive processes during design: The effects of color. Design Studies, 30, 521-540.

Dijksterhuis, A., \& Bargh, J. A. (2001). The perception-behavior express-way: The automatic effects of social perception on social behavior. In M. P. Zanna (Ed.), Advances in experimental social psychology, (Vol. 33, pp. 1-40). San Diego, CA: Academic Press.

Elliot, A. J., Maier, M. A., Binser, M. J., Friedman, R., \& Pekrun, R. (2009). The effect of red on avoidance behavior in achievement contexts. Personality and Social Psychology Bulletin, 35, 365-375.

Elliot, A. J., Maier, M. A., Moller, A. C., Friedman, R., \& Meinhardt, J. (2007). Color and psychological functioning: The effect of red on performance attainment. Journal of Experimental Psychology: General, 136, 154-168.

Elliot, A. J., \& Niesta, D. (2008). Romantic red: red enhances men's attraction to women. Journal of Personality and Social Psychology, 95, 1150-1164.

Frank, M. G., \& Gilovich, T. (1988). The dark side of self- and social perception: Black uniforms and aggression in professional sports. Journal of Personality and Social Psychology, 54, 74-85.

Friedman, R. S., \& Förster, J. (2001). The effects of promotion and prevention cues on creativity. Journal of Personality and Social Psychology, 81, 1001-1013.

Friedman, R. S., \& Förster, J. (2002). The influence of approach and avoidance motor actions on creative cognition. Journal of Experimental Social Psychology, 38, 41-55.

Friedman, R. S., \& Förster, J. (2005). Effects of motivational cues on perceptual asymmetry: Implications for creativity and analytical problem-solving. Journal of Personality and Social Psychology, 88, 263-275.

Higgins, E. T. (1997). Beyond pleasure and pain. American Psychologist, 52, 1280-1300.

Hill, R. A., \& Barton, R. A. (2005, May 19). Red enhances human performance in contests. Nature, 435, 293.

Kavakli, M., Scrivener, S. A. R., \& Ball, L. J. (1998). Structure in idea sketching behavior. Design Studies, 19, 485-517.

Lockwood, P., Jordan, C. H., \& Kunda, Z. (2002). Motivation by positive or negative role models: Regulatory focus determines who will best inspire us. Journal of Personality and Social Psychology, 83, 854-864.

Maier, M. A., Elliot, J. A., \& Lichtenfeld, S. (2008). Mediation of the negative effect of red on intellectual performance. Personality and Social Psychology Bulletin, 34, 1530-1540.

Mednick, S. A. (1962). The associative basis of the creative process. Psychological Review, 69, 220-232.

Mehta, R., \& Zhu, R. J. (2009). Blue or red? Exploring the effect of color on cognitive task performances. Science, 323, 1226-1229.

Zhong, C. B., Dijksterhuis, A., \& Galinsky, A. D. (2008). The merits of unconscious thought in creativity. Psychological Science, 19, 912-918. 